International Journal of Motor Control and Learning (IJMCL)

\title{
The Effect of Two Methods of Motor Program and Computer Games on the Fine Motor Skills in Children with Down Syndrome Disorder
}

\author{
Ayoub Hashemi $^{a *}$, Elahe Arabameri ${ }^{b}$
}

aph.D Student, Motor Behavior, University of Tehran, Tehran, Iran

${ }^{\mathrm{b}}$ Associated Professor, Motor Behavior, University of Tehran, Tehran, Iran

\begin{tabular}{|c|c|}
\hline Keywords & Abstract \\
\hline Computer game & \multirow{5}{*}{$\begin{array}{l}\text { Background: Down syndrome is one of the most common congenital chromosomal } \\
\text { abnormalities. } \\
\text { Objective: This study aimed to investigate the effects of two methods of motor } \\
\text { program and computer games on fine motor skills in children with Down syndrome } \\
\text { disorder. } \\
\text { Methods: For this purpose, } 45 \text { students who were studying in exceptional schools } \\
\text { in Tehran province were selected by available sampling methods. Following the } \\
\text { homogenizing of the scores in the pretest, participants were divided into three } \\
\text { groups of } 15 \text { people including two experimental groups (motor program and } \\
\text { computer game groups) and one control group. Experimental groups participated in } \\
\text { selective games for } 10 \text { weeks, three } 40 \text {-minute sessions a week. There were BOTMP }\end{array}$} \\
\hline & \\
\hline & \\
\hline Fine motor skills & \\
\hline Motor program & \\
\hline Ayoub Hashemi & before and after the intervention in order to collect the test data. T-tests (dependent) \\
\hline Email: ayoubhashemi10@yahoo.com & and co-variance were used to compare the results. \\
\hline Received: 2019/05/05 & \multirow{4}{*}{$\begin{array}{l}\text { Results: The results showed that there is a significant difference between the groups } \\
\text { of computer games and motor program in comparison with the control group in } \\
\text { terms of fine motor skill (respectively } \mathrm{P}=0.001, \mathrm{P}=0.007 \text { ). The results also showed } \\
\text { that there is not a significant difference between the two groups of computer games } \\
\text { and the motor program in fine motor skill ( } \mathrm{P} \geq 0.05 \text { ). } \\
\text { Conclusion: It seems that the correct use of computer games and motor program } \\
\text { interventions can improve motor skills in children with Down syndrome disorder. }\end{array}$} \\
\hline Accepted: 2019/08/06 & \\
\hline Published: 2019/08/25 & \\
\hline & \\
\hline
\end{tabular}

\section{Introduction}

Children's motor development changes throughout their life. We see social-psychological changes along with motor changes, so paying attention to children motor development is in fact paying attention to their perceptual-sensory skills development because movement is a suitable and acceptable platform for the development of perceptual, social and emotional skills(Lloyd, Burghardt, Ulrich, \& Angulo-Barroso, 2007). A child who has not the ability to master the skills, required to be mastered in his/her age, is expected to suffer serious developmental and behavioral abstinence because of abandonment in the games. 
In other words, motion is considered to be the developmental source of all the children's existential dimensions. For this reason, "motor development" is the main dimension and the basis of human development (Zarezadeh, Farokhi, \& Kazemnejad, 2010). Down syndrome, is the most common cause of mental retardation characterized with a myoschromosomal pattern, which typically results in specific facial features and other ones such as microcephaly and short stature (Lloyd et al., 2007). The incidence of this disorder varies from country to country and ranges from 1 in 700 to 1 in 900 live births (Greiremeyer \& Asswald, 2010). This syndrome is one of the most common genetic disorders which is associated with general musculoskeletal hypothyroidism, motor skills problems such as extreme movements of extremities, gross motor skills, equilibrium movements, running speed, strength, and visual motor control (Faghihi \& Esmaeili, 2015). Some of the common characteristics in children with Down syndrome can also affect their fine motor skills development. These features include hypotension, ligament and joint dislocation, short limbs, single hands, palms, hands smaller than normal children, lack of some of the wrist bones at the beginning of the birth and fifth finger curvature, heart problems, Infectious diseases, visual problems, and delayed cognitive development (Zarezadeh et al., 2010). Spano et al (2004) reported in a study that children with Down syndrome are severely damaged in all aspects of fine motor skills and a not grown to fit the age. Some researchers have looked at the impact of the exercise program on the skills of child manipulation, and their results have shown that the implementation of the curriculum would increase the skills of manipulation. Akbari (2006) showed that native-local games had more influential effects on the development of pediatric fundamental motor skills rather than common activities (Akbari, 2006). Also, Sha'al, Shaterzadeh \& Salehi (2006) examined the effects of physical and mental training on the coordination of the eyes and hands in young people. The results showed significant effects of physical and mental training on improving the coordination of the eyes and hands (Sha'al, Shaterzadeh, \& Salehi, 2006). Additionally, Hadian, Abduli, Mortazavi, Bagheri \& Jalili (2007), in a research on the hand skills of mentally retarded children aged 7-10 years, showed that eyes and hands coordination exercises improve manipulation skills and manual coordination. Gharayi, Arab Ameri and Homanian (2014) also carried out a study entitled "Enrichment (Perceptual-Motor and Music) of the Environment on the Growth of Fine and Gross Movements of Children". The results showed that the perceptual-motor and musical experience has a positive effect on motor development in general and on the age equivalent of gross and fine movements (Gharayi, Arab ameri, \& Homanian, 2014). Momeni, Sohrabi, Taheri \& Ghasemi (2015) also examined the effect of eight weeks of selected sport exercises on perceptual-motor skills in 7-13 years old healthy girls with Down syndrome (Momeni, Sohrabi, Taheri, \& Ghasemi, 2015). 
Computers, On the other hand, make up almost the entire human life nowadays, and like other man-made artifacts, they are also a double-edged sword. On the one hand, it could be used rightfully to raise the accuracy of work and take advantage of its benefits. On the other hand, it may be used incorrectly, which sometimes causes damage. In the computer world, what attracts the adolescents more is what they call "computer games". Computer games are one of the students' entertainments in the new era. These exciting games of watches put children and teens in front of the screen and bring them down from the real world to the imagination. In addition to children and adolescents, we also have seen adults who are sitting in front of the monitor with excitement and enthusiasm and drowning in the game, so that it completely separates them from their surroundings. In gaming, gamers do their best to level up. Teenagers usually take their passwords from their friends or even trade them. Overcoming obstacles and reaching the higher stages creates excitement and joy in the player and defeat makes them anxious (Faghihi \& Esmaeili, 2015). According to some researchers, computer games are a cognitive activity that can improve cognitive skills and visual-motor perception (Greiremeyer \& Asswald, 2010). Some researchers such as Sims \& Mayers (2002) and Green \& Bavelier (2006) emphasize the positive effects of computer games on eye-hand coordination. Delvari (2008) confirmed the positive effects of computer games on perceptualmotor skills and performance accuracy. Even in children with hemiplegia, sensory-motor games in the virtual environment improve visual-motor coordination and motor coordination in the upper extremity (Rostami, Javadipour, Ghanbari, Azizi, \& Amiri, 2012)., After many studies, Goldstein (2006) concluded that the applications of computer games could possibly practice cognitive and cognitive skills, leading to develop a sense of cooperation, and ultimately to entertainment. However, along with the positive results of some computer games, Ahmadi (2002), during a research study, showed that students who play computer games, express more violence and aggression and less social participation compared to those who do not play computer games. In addition, gamers' social and cultural alienation is much higher. Although the effects of motor exercise and computer games on the motor skills of normal children have been confirmed, less effect has been observed for these interventions on the performance of children with mental disorders, especially those with Down syndrome. Considering that limited number of national and foreign studies have investigated the effects of motor curricula and computer programs on the development of children with Down syndrome disorder, and considering also the importance of these programs on the growth of children with Down syndrome especially in the early years of life, we decided to study this rather intact subject. Most of the studies that have been done in this field are of a causal-comparative nature and not much intervention has been made. Therefore, the aim of our study is to conduct training and exercise interventions (motion and video) so that we can 
examine the effects of these training interventions on the development of fine motor skills in children. The researchers are determined to determine whether the exercise program improves the fine motor skills of children with Down syndrome. Do computer games improve the fine motor skills of children with Down syndrome? Which of these two interventions has a greater impact on improving the fine motor skills of children with Down syndrome?

\section{Method}

The present study is a quasi-experimental one with two experimental and control groups. All of the statistical population of this study consisted of children with Down syndrome disorder in exceptional schools of Tehran province ranging from 9 to 14 years old. To determine the sample size, 45 boys from exceptional schools in Tehran province were selected by targeted and available sampling methods. They were divided into three groups after homogenization of the pre-test scores. The inclusion criteria included children with Down syndrome, trained intelligence, and age of 9 to 14 years. The child was excluded from the study in the absence of a child's collaboration or his/her disease, discontinuation of the sessions by child or family's unwillingness to continue the treatment. Information about the diagnosis and the student's intelligence status were obtained by referring to the medical records available at the school.The research tools included motor skills training program, computer games and $\mathrm{BOTMP}^{1}$.The motor skills training program included neuromuscular power, flexibility, balance, power, aerobic power, muscular strength, ball-balance skill, reaction speed, ball-to-balance skill, aerobic power, power coordination, and reaction speed (Farhat, Hsairi, Baati, Smits-Engelsman, \& Masmoudi, 2016). The computer games program included Disk Shooting, Balls \& Boxes, Jumping Arrows, Color Balls, Thanks Given Dinner, Spot the difference, Monkey Banana, Row Swap Puzzle, and Trick or Treat (Martinovic, Burgess, Pomerleau, \& Marin, 2015). At the beginning, the researcher, after the administrative procedures, attaching a letter for coordination and cooperation, clarifying the subject of the research for the administrators and other officials of the centers of action, was introduced to the relevant schools with the coordination of the Tehran Education Directorate and an excuse with the teachers. Written consent from the parents of participants in the research was also gathered. Then, a questionnaire was prepared in which factors such as age, height, and weight were answered by the teachers. Information was collected in two weeks after the distribution and completion of the questionnaire and a sample of 45 individuals was provided under two intervention programs, the motor program and computer games. The research tool in the study was the Bruininks-Oseretsky Expedition Test, a valid test with a validity of 0.89 for measuring the fine motor skills of children aged 4-14 years. This test is a diagnostic tool for identifying pediatric motor disorders and consists of eight subtasks. The retest reliability coefficient 
of this test, which has two long and short forms, is reported to be 0.86 and 0.87 respectively (Farhat et al., 2016). The score in this test was based on a number of specific and standard tests that are available for each subtest and the subject must repeat each one twice. Finally, the examiner recorded the scores and collected them together. The highest score of two repetitions was considered as the individual's score. Relevant to the purpose of the research, the researcher used subscales of response speed, visual motor-control and upperlimb speed dexterity of the Bruininks-Oseretsky test. To obtain a general score of fine motor skill, the scores of the whole subscales were normalized first. Subsequently, they subdivided the scores of the subtest tests into a general score of fine motor skills (Ashtari, Farokhi, Sheikh, Namazizadeh, \& Naghdi, 2016). In the pre-test phase, each subject completed the Burininks-Oseretsky test, and the score for the subjects was recorded. In the next step, the subjects were randomly assigned to three groups of 15 individuals and performed the interventions. A group of subjects went to the exercise program. The second group performed computer programs, and no specific program was provided for the control group. Intervention exercises were conducted in two groups of exercise programs and computer programs for 10 weeks, three 40 minutes sessions per week. The subjects in the study were asked to refrain from performing other exercise programs during the course of the research. In order to conduct a thorough research, experts from special centers were used by the researcher; they oversaw the implementation of interventions. At the end of the training sessions, the Burininks-Oseretsky test was performed again in three training group. In this research, descriptive and inferential statistics were used to categorize and set the data. Before applying parametric statistical tests, its assumptions for normalization of data were investigated by Shapiro-Wilk test and homogeneity of variances through Levene's test. In order to determine the difference intra groups, t-test was used and co-variance was used to examine the difference inter groups. The LSD post hoc test was also used to observe the location of the differences. The significance level for all variables was considered as $\mathrm{P}<0.05$. All statistical analyzes were performed using SPSS 22 software.

\section{Results}

Table 1 shows the demographic characteristics of the experimental and control groups. Also, the results of one-way ANOVA showed that there was no significant difference between age, height and weight in any of the research groups, so the triple groups of the research were homogeneous in terms of the distribution of the variables mentioned.

The results of the Shapiro-Wilk test indicated that the distribution of data was normal in the pretest and post-test stages in all studied groups. Also, the results of Levene's test on the motor skills variable in the pre-test $(\mathrm{P}=0.68, \mathrm{~F}=0.44)$ and posttest $(\mathrm{P}=0.64, \mathrm{~F}=0.58)$ was not significant $(\mathrm{P}>$ 0.05). This fact indicates the homogeneity of variances.

Considering the value of significance obtained from the dependent t- test and its comparison with 
the significance level considered for the test ( $\mathrm{P}$ $=0.05)$, it is considered that there is a significant difference between the pre-test and post-test scores in both groups of intervention (Table 2).

Table 1. Descriptive and Inferential Indices of Age, Weight and Height of the Subjects in the Three Experimental Groups.

\begin{tabular}{|c|c|c|c|c|c|c|}
\hline Variable & Group & Number & $\mathrm{M} \pm \mathrm{SD}$ & $\mathrm{F}$ & Df & Sig \\
\hline \multirow{3}{*}{ Age } & Motor Program & 15 & $12.87 \pm 1.67$ & \multirow{3}{*}{0.45} & \multirow{3}{*}{$(2,43)$} & \multirow{3}{*}{0.67} \\
\hline & Computer Game & 15 & $12.65 \pm 1.89$ & & & \\
\hline & Control & 15 & $12.50 \pm 1.97$ & & & \\
\hline \multirow{3}{*}{ Weight } & Motor Program & 15 & $38.50 \pm 2.67$ & \multirow{3}{*}{0.67} & \multirow{3}{*}{$(2,43)$} & \multirow{3}{*}{0.56} \\
\hline & Computer Game & 15 & $38.30 \pm 2.75$ & & & \\
\hline & Control & 15 & $38.65 \pm 2.43$ & & & \\
\hline \multirow{3}{*}{ Height } & Motor Program & 15 & $144.7 \pm 3.54$ & \multirow{3}{*}{0.59} & \multirow{3}{*}{$(2,43)$} & \multirow{3}{*}{0.63} \\
\hline & Computer Game & 15 & $143.9 \pm 3.76$ & & & \\
\hline & Control & 15 & $144.5 \pm 3.34$ & & & \\
\hline
\end{tabular}

*Significance level $\mathrm{P} \leq 0.05$.

Table 2. Results of the Dependent T- test of Experimental and Control Groups on Fine Motor Skills.

\begin{tabular}{|c|c|c|c|c|}
\hline variable & groups & stage & $\mathrm{MD} \pm \mathrm{SD}$ & $\mathrm{P}$ \\
\hline \multirow{6}{*}{ Response Speed } & \multirow{2}{*}{ Computer Game } & Pretest & $1.68 \pm 0.54$ & \multirow{2}{*}{$0.013^{*}$} \\
\hline & & Posttest & $3.20 \pm 0.98$ & \\
\hline & \multirow{2}{*}{ Motor Program } & Pretest & $1.65 \pm 0.64$ & \multirow{2}{*}{$0.001^{*}$} \\
\hline & & Posttest & $3.16 \pm 0.95$ & \\
\hline & \multirow{2}{*}{ Control } & Pretest & $1.66 \pm 0.34$ & \multirow{2}{*}{0.123} \\
\hline & & Posttest & $1.89 \pm 0.87$ & \\
\hline \multirow{6}{*}{ Visual-motor Control } & \multirow{2}{*}{ Computer Game } & Pretest & $1.96 \pm 1.05$ & \multirow{2}{*}{$0.007^{*}$} \\
\hline & & Posttest & $3.43 \pm 1.20$ & \\
\hline & \multirow{2}{*}{ Motor Program } & Pretest & $1.86 \pm 1.04$ & \multirow{2}{*}{$0.001^{*}$} \\
\hline & & Posttest & $3.39 \pm 1.15$ & \\
\hline & \multirow{2}{*}{ Control } & Pretest & $1.99 \pm 1.20$ & \multirow{2}{*}{0.245} \\
\hline & & Posttest & $2.23 \pm 1.07$ & \\
\hline \multirow{6}{*}{$\begin{array}{c}\text { Upper- limb Speed } \\
\text { Dexterity }\end{array}$} & \multirow{2}{*}{ Computer Game } & Pretest & $8.23 \pm 3.18$ & \multirow{2}{*}{$0.005^{*}$} \\
\hline & & Posttest & $11.45 \pm 3.35$ & \\
\hline & \multirow{2}{*}{ Motor Program } & Pretest & $8.15 \pm 3.10$ & \multirow{2}{*}{$0.004^{*}$} \\
\hline & & Posttest & $11.05 \pm 3.30$ & \\
\hline & \multirow{2}{*}{ control } & Pretest & $8.29 \pm 3.23$ & \multirow{2}{*}{0.236} \\
\hline & & posttest & $8.97 \pm 3.42$ & \\
\hline
\end{tabular}

* Significance level $\mathrm{P} \leq 0.05$.

According to the results obtained in Table 3, covariance $(\mathrm{F}(2,42)=36.29, \mathrm{P}=0.001$, Eta square $=0.732$ ) is significant. As Eta square out, the training programs used in this study have caused changes in the dependent variable (fine motor skills).

LSD post hoc test was used to find out more precisely which of the two methods of training had more effectiveness in improving fine motor skills. Its results are presented in Table 4. According to the results of Table 4, the difference in the total scale of fine motor skills between the computer game and motor program groups with the control group is significant (respectively $\mathrm{P}=0.001, \mathrm{P}=0.007$ ). Thus, both interventional groups compared with the control group has been shown to improve the fine motor skills of children with Down syndrome. However, the results of the LSD Post hoc also showed that there is not a significant difference between the two groups of computer games and the motor program in 
terms of fine motor skill ( $\mathrm{P} \geq 0.05)$. This means that there is not a significant difference between the effect of the computer game program and the motor program on improving the fine motor skills of children with Down syndrome.

Table 3. Results of Covariance Analysis of Two Experimental and Control Groups in Fine Motor Skills.

\begin{tabular}{cccccccc}
\hline $\begin{array}{c}\text { Indicator } \\
\text { Source of Change }\end{array}$ & Sum of squares & DF & $\begin{array}{c}\text { Average of } \\
\text { Squares }\end{array}$ & F & P & Eta Square & Power \\
\hline Fine Motor Skill & 1345.123 & 1 & 1354.123 & 67.35 & $0.000^{*}$ & 0.754 & 0.98 \\
\hline Group & 1136.85 & 2 & 568.425 & 36.29 & $0.001^{*}$ & 0.732 & 0.97 \\
\hline Error & 387.47 & 42 & - & - & - & - & - \\
\hline Sum & 2880.443 & 45 & & & & &
\end{tabular}

*Significance level $\mathrm{P} \leq 0.05$.

Table4. LSD Follow-up test in the Element of Fine Motor Skills.

\begin{tabular}{ccccc}
\hline Group(I) & Group(j) & Difference of Meanings & Standard Deviation & $\mathrm{p}$ \\
\hline \multirow{2}{*}{ Computer game } & Motor Program & 0.56 & 1.01 & 0.067 \\
& Control & 3.64 & 1.78 & $0.001^{*}$ \\
\hline \multirow{2}{*}{ Motor program } & Computer Game & -0.56 & 1.01 & 0.067 \\
& Control & 3.23 & 1.84 & $0.007^{*}$ \\
\hline \multirow{2}{*}{ control } & Computer Game & -3.64 & 1.78 & $0.001^{*}$ \\
& Motor Program & -3.23 & 1.84 & $0.007^{*}$ \\
\hline
\end{tabular}

*Significance level $\mathrm{P} \leq 0.05$.

\section{Discussion}

The findings of this study showed that computer games improved the fine motor skill in children with Down syndrome. The results of this study are consistent with the results of Delvari (2008) and Sha'al et al (2006) on increasing perceived-motor skills and student's accuracy in computer games. Also, the results of this study are consistent with the results of Sims \& Mayer (2002) and Goldstein (2006) concerning the positive effect of computer games on motor coordination. According to Green et al (2006), computer games improve visual processing at various levels and increase the ability of individuals to complete complicated vision tasks. However, the findings of the present study contradict the results of Straker,
Howie, Smits, Jensen \& Piek (2015). Straker et al (2015) who examined the effect of computer games on motor coordination in children with developmental coordination disorder; their results showed that access to a wide range of active home video games could not improve the motor skills of children with developmental disorder. The reason for the differences between our research findings and that of Straker et al (2015) may be different types of exercise protocols and different subjects involved in the two studies. The effect of computer games could also be explained based on the cognitive theories. Cognitive theories focus on neurobiological processes (Delvari, 2008). Computer games are cognitive activities that can enhance cognitive skills and visual - motor skills and enhance the ability to organize and 
concentrate. Computer games also increase the speed of information processing. While working with a computer and along with receiving visual information and visual perception, there must be a simultaneous coordination between the brain program and the movement of the hands and fingers. Computer games also improve visual processing at various levels, and increase the ability of individuals to complete complex vision tasks (Faghihi \& Esmaeili, 2015). Despite the benefits of computer games to some aspects of cognitive and motor skills, it is still unclear whether these benefits are due to strategic changes or changes made to the fundamental aspects of visual processing. Therefore, finding out the answer requires more research (Delvari, 2008). In fact, some studies have shown that to benefit from computer games that enhance cognitive skills and avoid their harmful effects, these games must be controlled and parents must schedule computer games for children to avoid excessive use of it (Goldstein, 2006). There are also different opinions about the positive or negative effects of computer games. It seems that the type of game and its content can be decisive in this regard. In the current situation, to prevent the social and cultural damaging effects of these games, educators have been working to create a focal point for children and adolescents for the development of appropriate climate games. Cultural and ethical issues of the Iranian society to act in addition to physical and motor activities of children, can help develop the motor, cognitive and child's dimension (Ahmadi, 2002). Also, the findings of this study showed that a course of motor exercise program leads to development of fine motor skills in children with Down syndrome. This finding is based on the results of Sha'al et al (2006), Rostami et al (2012), Amini \& Jaberimghdam (2015), Momeni et al (2015), Salman \& Amini (2014). In explaining this finding, possible improvement of motor skills in children with Down syndrome through motor exercise programs, it can be said that psycho-motor skills are in association with the ability to learn the processes. These abilities help the child evaluate their performance and assess possible obstacles and rate of progress. Therefore, by enriching the environment and setting up group games, psychomotor skills will be improved, because these skills are acquired through experience, education and learning (Amini \& Jaberi Moghadam, 2015). However, the results of this study are inconsistent with the findings of Andriolo, Dib, Ramos \& Atallah (2010). The reason for the difference in the results may be the application of different subjects and different training protocol. Wang's (2004) also shows that the 3-week creative motion program (two sessions per week for 30 minutes) has no significant effect on the balance skills (Amini \& Jaberi Moghadam, 2015).

\section{Conclusions}

The final and important result seen in this study was that two interventions in the research (computer games and motor programs) had a similar effect on the fine motor skills of the participating children. Therefore, there was not a significant difference between the effect of 
computer games and motor skills training program on the fine motor skills of children with Down syndrome. This finding is consistent with the results of Ahmadzadeh, Abdi \& Farrokhi (2014). Ahmadzadeh et al (2014) studied the effects of computer games and local native game on the coordination of the eyes and hands of children aged 7-10 years. Their results showed that although the effect of computer games and local - native games improved the coordination of the eyes and hands of children, there was not a significant difference between motor skills in the two groups. One possible reason for this result consistency in these two groups might be the motivated dimension of computer games in children who have not had any previous work experience with computers and thus have made more efforts. The investigator's goal was not conscious. Children with Down Syndrome need to improve their executive functions because research has shown that these children are weaker in their executive functions than their regular counterparts. On the other hand, as the tasks of these children become more difficult or delayed, their weaknesses in coordination and management of their behavior increase, which is indicative of their weaknesses and failures in executive functions (Kohpai, 2011). Motor programs and related computer games, will be very useful and constructive not only for those children in preschool and primary school, but also for many normal and normal children in these age groups. Physical education specialists can help parents, educators, and educational authorities and child care providers in designing and implementing such programs. Paying attention to the motor development of children not only helps parents to identify some developmental disorders, but also provides a good basis for parents and educators to thoroughly develop their child's development (Ahmadzadeh, Abdi, \& Farrokhi, 2014). According to the results of this study, motor program and computer games can be used as a treatment method for children with Down syndrome, or at least as a complementary method. It can be used in combination with other methods available in treatment of these children as well. Psychologists, pedagogical educators and in educators adapted physical activity teachers and parents, can use the results of this study to improve the fine motor skills of children with Down syndrome. The limitations of the present research were the lack of measurement of internal motivation, mental status, and out of field activities. Other limitations of this research are low size of the sample and non-random selection of subjects. It is suggested that the effects of motor program and computer games on the executive function and stereotypical performances of these children be examined. In addition, increasing the sample size and prolonging the training period in subsequent studies might be helpful to reach the definitive results and generalize these results.

\section{Acknowledgments}

All of the participants in this study, as well as all the hardworking staff and occupational therapists from the exceptional schools in Tehran, are appreciated for this research. 


\section{Funding}

This research received no specific grant from any

funding agency in the public, commercial, or notfor-profit sectors.

\section{Conflict of interests}

The authors declare that there is no conflict of interest.

\section{References}

1. Ahmadi, S. (2002). The study of the social effects of computer games on male students of secondary school in Isfahan. Research Project, Esfahan [In Persian].

2. Ahmadzadeh, Z., Abdi, M., \& Farrokhi, A. (2014). The impact of local computer and local games on the coordination of the eyes and hands of children aged 7 to 10 years. Journal of Motion Behavior(14), 6172 [In Persian].

3. Akbari, H. (2006). The Impact of Local Native Game and Development of Cognitive-Cognitive Skill in 7 Year Old Boys Master's Thesis. Tehran, Tarbiat Modares University. [in Persian].

4. Amini, H., \& Jaberi Moghadam, A. (2015). Effect of gymnastic exercises on neuropsychological characteristics of children with developmental coordination disorder. Journal of Decelopment and Motor Learning, 7(2), 217-238 [In Persian].

5. Ashtari, M., Farokhi, A., Sheikh, M., Namazizadeh, M., \& Naghdi, N. (2016). The effect of training in water with and without Dolphin on gross motor skills of 8 years old children with autism spectrum disorder. Journal of motor behavior, 8(23), 171-184 [In Persian].

6. Delvari, M. (2008). Effect of Computer Games on Perceived Skill and Performance Precision. Master's Thesis, University of Orumieh. [in Persian].

7. Faghihi, M., \& Esmaeili, Z. (2015). The Effect of Computer Games on the Learning of Elementary School Students (Case Study: Elementary School of Salehin; District 14 of Tehran). World Conference on Psychology and Educational Sciences, Law and Social Sciences at the Beginning of the Third Millennium. [In Persian].

8. Farhat, F., Hsairi, I., Baati, H., Smits-Engelsman, B., \& Masmoudi, K. (2016). The effect of a motor skills training program in the improvement of practiced and non-practiced tasks performance in children with developmental coordination disorder (DCD). Journal of Human Movement Science(46), 10-22.

9. Gharayi, F., Arab ameri, E., \& Homanian, D. (2014). Constantinople, D Impact of enrichment (perceptual-motor and musical) on the age-related equilibrium of delicate movements in children aged 5-8 months. Journal of Development and Motor Learning, 6(1), 75-89 [In Persian].

10. Goldstein, J. (2006). Applied Research in Video Games, Gaming.

11. Greiremeyer, T., \& Asswald, S. (2010). Effects of prosocial behavior. Journal of Personality and Social Psychology(98), 211-221.

12. Kohpai, H. (2011). Rehabilitation of Children with Down Syndrome, A Guide to Applicants for Coaches and Mothers. Honest Book.

13. Lloyd, M. C., Burghardt, A., Ulrich, D. A., \& Angulo-Barroso, R. M. (2007). Relationship between early physical activity and motor milestone achievement in infants with Down syndrome. Journal of Sport \& Exercise Psychology, 29.

14. Martinovic, D., Burgess, G. H., Pomerleau, C. M., \& Marin, C. (2015). Comparison of children's gaming scores to NEPSY-II scores: Validation of computer games as cognitive tools. Computers in Human Behavior, 49, 487-498.

15. Momeni, M., Sohrabi, M., Taheri, H., \& Ghasemi, A. (2015). Effect of exercise activities on cognitivemotor skills of children with Down syndrome. Journal of Rehabilitation, 16(2), 168-175 [In Persian].

16. Rostami, H., Javadipour, H., Ghanbari, S., Azizi, M., \& Amiri, R. (2012). The effect of sensorymovement games in the playing environment on the coordination of the eyes and hands of children with hemiplegic cerebral palsy. Bachelor of Science, Shahed University, 19(95), 45-54 [In Persian].

17. Sha'al, S., Shaterzadeh, Y., \& Salehi, R. (2006). Investigating the effect of mental training on eye and hand coordination in healthy girls 20-25 years. Journal of Rehabilitation, 7(3), 4-12 [In Persian].

18. Zarezadeh, M., Farokhi, A., \& Kazemnejad, A. (2010). Determination of reliability and validity of a large motor growth test in children aged 3 to 11 years in Tehran. Journal of Olympics, 4(52), 85-98 [In Persian]. 